\title{
Current status of robot-assisted surgery
}

\author{
Ada TL Ng, PC Tam *
}

\section{A B S T R A C T}

The introduction of robot-assisted surgery, and specifically the da Vinci Surgical System, is one of the biggest breakthroughs in surgery since the introduction of anaesthesia, and represents the most significant advancement in minimally invasive surgery of this decade. One of the first surgical uses of the robot was in orthopaedics, neurosurgery, and cardiac surgery. However, it was the use in urology, and particularly in prostate surgery, that led to its widespread popularity. Robotic surgery, is also widely used in other surgical specialties including general surgery, gynaecology, and head and neck surgery. In this article, we reviewed the current applications of robot-assisted surgery in different surgical specialties with an emphasis on urology. Clinical results as compared with traditional open and/or laparoscopic surgery and a glimpse into the future development of robotics were also discussed. A short introduction of the emerging areas of robotic surgery were also briefly reviewed. Despite the increasing popularity of robotic surgery, except in robot-assisted radical prostatectomy, there is no unequivocal evidence to show its superiority over traditional laparoscopic surgery in other surgical procedures. Further trials are eagerly awaited to ascertain the long-term results and potential benefits of robotic surgery.

\section{Hong Kong Med J 2014;20:241-50}

DOl: 10.12809/hkmj134167

ATL Ng, FRCSEd (Urology), FHKAM (Surgery)

PC Tam *, FRCSEd (Urology), FHKAM (Surgery)

Department of Surgery, The University of Hong Kong, Queen Mary Hospital, Pokfulam, Hong Kong

assisted radical prostatectomy is available at $<w w w . h k m j . o r g>$

\section{Introduction}

The introduction of robot-assisted surgery, and specifically the da Vinci Surgical System, is one of the biggest breakthroughs in surgery since the introduction of anaesthesia, and represents the most significant advancement in minimally invasive surgery of this decade. One of the first surgical uses of the robot was in orthopaedics, neurosurgery, and cardiac surgery. However, it was the use in urology, and particularly in prostate surgery, that led to its widespread popularity. ${ }^{1}$ Robotic surgery is also widely used in other surgical specialties including general surgery, gynaecology, and head and neck surgery.

Urology has long been adoptive to advances in technology. It is not surprising that soon after robotic technology was first applied to medical science, it was well received by the urology community. Robotic surgery has applications in many aspects of urological surgery. Since 1998, there have been over 4000 peer-reviewed publications in various specialties on the da Vinci Surgery, of which $46 \%$ pertain to urology, $17 \%$ to cardiothoracic surgery, $13 \%$ to general surgery, $8 \%$ to gynaecology, $7 \%$ to general surgical topics (including outcomes, trends, and cost-effectiveness for different types of robotic surgery), $4 \%$ to paediatric surgery, and $2 \%$ to otorhinolaryngology. ${ }^{2}$

Literature review of current applications of robotics in different surgical specialties with an emphasis on urology was performed. Clinical results as compared with traditional open and/or laparoscopic surgery and a glimpse into the future development of robotics will be discussed. A short introduction on emerging areas of robotic surgery will also be briefly reviewed.

\section{History of the surgical robot}

The world's first surgical robot, 'Arthrobot', was born in 1983 and was designed to assist orthopaedic procedures. In 1985, PUMA 560 (Unimate, New Jersey, US) was used to precisely place a needle for computed tomography-guided brain biopsy. This was followed in 1988 by ROBODOC (Integrated Surgical Systems, Delaware, US), a system used in total hip arthroplasty to allow precise preoperative planning, and to mill out precise fittings in the femur for hip replacement. The first application in urology occurred in 1988 at Imperial College (London, UK) with the use of the PROBOT in clinical trials to perform transurethral surgery. In 1993, Computer Motion, Inc (Santa Barbara [CA], US) - the original leading medical robots supplier-released AESOP (Automated Endoscopic System for Optimal Positioning), a robotic arm to assist in laparoscopic camera holding and positioning. The CyberKnife (Accuray, Sunnyvale [CA], US) was introduced in 1994 for stereotactic radiosurgery in neurosurgery. 


\section{機器人手臂輔助手術的現況}

吳翠蓮、談寶雛

機器人手臂輔助手術的引進, 尤其是達文西手術系統, 是手術引進麻 醉以來最大的突破之一, 代表着這十年間微創手術最顯著的進步。骨 科、神經外科和心藏外科手術率先採用機器人輔助。然而, 正是泌尿 外科 (特別是前列腺手術) 導致機器人輔助的廣泛普及。機器人手臂 輔助手術也廣泛應用於其他外科專科, 包括外科、婦科和頭頸部手 術。本文回顧機器人輔助手術在不同外科專業目前的應用, 特別針對 泌尿外科方面, 以及討論機器人輔助手術的臨床效果, 並與較傳統的 開放和腹腔鏡手術比較, 來窅探機器人技術的未來發展。此外, 亦會 簡短回顧機器人手術在泌尿科應用的新興領域。儘管機器人手術日漸 普及, 除了機器人輔助根治性前列腺切除術, 目前並沒有明確證據顯 示機器人手術在其他外科手術優勝於傳統的腹腔鏡手術。須作進一步 的試驗評估機器人手術的長遠和潛在效益
The year 1998 was a significant landmark, with the introduction of ZEUS Robotic Surgical System (Computer Motion, Inc) and the da Vinci Surgical System (Intuitive Surgical, Inc, Sunnyvale [CA], US). Both systems comprised a surgical control centre and robotic arms. The first da Vinci robotic surgical procedure was a robot-assisted heart bypass, and it took place in Germany in $1998 .^{3}$ In 2000, the da Vinci robot was given approval by the US Food and Drug Administration (FDA) for use in laparoscopic procedures. The first reported robot-assisted radical prostatectomy (RARP) took place in Paris, France, in the same year. ${ }^{4}$ Intuitive Surgical, Inc took over Computer Motion, Inc in 2003 and is now the sole company marketing robotic surgical devices. Other companies such as Olympus and Samsung are developing new robotic surgical systems, with a promise of lower cost and more compact machines.

\section{The da Vinci Surgical System}

The da Vinci Surgical System comprises three components: a surgeon's console, a patient-side robotic cart with four robotic arms manipulated by the surgeon (one to control the camera and three to manipulate instruments), and a high-definition three-dimensional (3D) vision system. Articulating surgical instruments are mounted on the robotic arms which are introduced into the body through cannulas. $^{2}$ The US FDA approved the system for general laparoscopic surgery (gallbladder diseases and reflux) in July 2000, for urological procedures in 2001, for mitral valve repair surgery in November 2002, and for gynaecological conditions in 2005.

\section{Advantages and cost-effectiveness of the robotic surgery system}

Robotic surgery by the da Vinci Surgical System (Intuitive Surgical, Inc) has been popularised by its widespread usage in radical prostatectomy (RP). The robotic system overcomes the limitations of the standard laparoscopic approach and allows for precise dissection in a confined space and hence the increasing application of robot-assisted laparoscopic prostatectomy in expert centres. These advantages include stable operator-controlled camera, highdefinition 3D magnified view of 10 to 12 times, articulating instruments with seven degrees of freedom, motion scaling, and tremor filtration. Moreover, carbon dioxide insufflation during the procedure helps in reduction of venous ooze, thus leading to improved visualisation and reduced blood loss. ${ }^{5}$ Across different specialties, the majority of robotic surgeries have been associated with a decreased length of stay, and fewer complications including a lower transfusion rate and in-hospital death rate. ${ }^{6}$ However, robot-assisted laparoscopic surgery is costlier than laparoscopic surgery and open surgery.

An analysis of new technology and health care costs of 20 different robot-assisted surgeries published in the New England Journal of Medicine in $2010^{7}$ showed that the use of the robot added $13 \%$ (US\$3200) to the total average cost of a procedure in 2007. However, there were no large-scale randomised trials to definitely show that robot-assisted surgery was superior to other procedures. ${ }^{7}$

Additional studies are needed to better delineate the comparative and cost-effectiveness of robot-assisted laparoscopic surgery relative to laparoscopic surgery and open surgery. Robotic surgery provides similar postoperative outcomes to laparoscopic surgery but has a reduced learning curve. Although costs are currently high, increased competition from manufacturers and wider dissemination of the technology may drive costs down. Further trials are needed to evaluate longterm outcomes in order to fully evaluate the value of robots in surgical procedures. ${ }^{8}$

\section{Application in urology}

There has been a continuous expansion of robotassisted surgery for both upper and lower urinary tract diseases in urology. This is especially true in robotic prostatectomy, where the initial reports of robotic prostatectomy by Menon et $\mathrm{al}^{9}$ led to an exponential growth of robotic surgery in clinically localised prostate cancer. More recently, there has been an increasing number of robotic renal surgeries $^{10}$ and robotic cystectomy in centres of excellence. ${ }^{11}$

\section{Robotic radical prostatectomy}

Prostate cancer is the most common solid organ malignancy in men in the US, and the second leading cause of cancer death. It is the second most 
common cancer in the world, with a world agestandardised rate of 28 per 100000 males. ${ }^{12}$ There is a rapidly increasing incidence of prostate cancer in Asian countries due to a more westernised lifestyle. ${ }^{13}$ In Hong Kong, prostate cancer is the third most common cancer, accounting for $10.7 \%$ of all male malignancies; it is the fifth major cause of cancer death, responsible for $4.1 \%$ of all cancer deaths in Hong Kong. ${ }^{14}$

Radical prostatectomy is a standard treatment option for localised carcinoma of the prostate, with a demonstrated survival advantage when compared with watchful waiting in the randomised controlled trial SPCG-4 (Scandinavian Prostate Cancer Group Study No. 4). ${ }^{15}$ Radical prostatectomy showed a significant relative risk reduction in cancer-specific mortality as compared with watchful waiting-44\% decrease at 10 years, $35 \%$ at 12 years, and $38 \%$ at 15 years..$^{15,16}$

However, open RP is associated with high morbidity rates. Schuessler et $\mathrm{al}^{17}$ introduced laparoscopic RP in 1997 with the aim of reducing morbidity. The advantages of laparoscopic prostatectomy, as reported in initial expert series, showed a lower mean blood loss and transfusion rate, decreased mean hospital stay, and earlier removal of the Foley catheter compared with results from open prostatectomy series. ${ }^{18}$

However, the technical demands of laparoscopic RP prevented its widespread use by the average urologist, with a limited case load. The introduction of the da Vinci Surgical System was a breakthrough in minimally invasive prostatectomy. Menon et $\mathrm{al}^{1}$ from the Vattikuti Urology Institute in Detroit [MI], US are responsible for the development and popularisation of RARP. This technique offers all the advantages of minimally invasive laparoscopic prostatectomy with the added advantage of shorter learning curve and improved ergonomics, leading to the widespread use and acceptance of RARP worldwide.

Ahlering et $\mathrm{al}^{19}$ studied the learning curve for robotic prostatectomies, and found that the robotic system might significantly shorten the learning curve for an experienced open yet laparoscopy-naïve surgeon. The learning curve for achieving 4-hour proficiency has been shown to be 12 patients. ${ }^{19}$

Robot-assisted RP has overtaken open RP as the most common surgical approach for RP ever since the FDA approval in 2001, and is estimated to account for approximately $80 \%$ of all RP procedures in the US. ${ }^{20}$

However, the rise in robotic procedures was initially not backed by any evidence on clinical benefits. No randomised trial showed the benefits of robotic surgery until the publication of the nationwide series by Trinh et al. ${ }^{21}$ Data from this series demonstrated superior adjusted perioperative outcomes after RARP in virtually all examined outcomes. Of 19462 RPs, $61.1 \%$ were RARPs, 38.0\% were open RPs, and $0.9 \%$ were laparoscopic RPs. In multivariable analyses, patients undergoing RARP were less likely to receive a blood transfusion (odds ratio $[\mathrm{OR}]=0.34 ; 95 \%$ confidence interval $[\mathrm{CI}], 0.28$ -

$0.40)$, to experience an intra-operative complication $(\mathrm{OR}=0.47 ; 95 \% \mathrm{CI}, 0.31-0.71)$ or a postoperative complication $(\mathrm{OR}=0.86 ; 95 \% \mathrm{CI}, 0.77-0.96)$, and to experience a prolonged length of stay $(\mathrm{OR}=0.28 ; 95 \%$ CI, 0.26-0.30) [Table 121].

A recent territory-wide review in Hong Kong ${ }^{22}$ showed that a total of 235 patients underwent RARP between 2005 and 2009, with a 37.3\% rate

TABLE I. Intra-operative and postoperative outcomes for open and robotic radical prostatectomy surgery ${ }^{21}$

\begin{tabular}{|c|c|c|c|c|}
\hline \multirow[t]{2}{*}{ Outcome } & \multicolumn{2}{|c|}{ No. (\%) } & \multirow{2}{*}{$\begin{array}{c}\text { OR (95\% Cl) } \\
\text { Robotic vs open }\end{array}$} & \multirow[t]{2}{*}{$P$ value } \\
\hline & Open $(n=7389)$ & Robotic (n=7598) & & \\
\hline Homologous blood transfusion & $572(7.7)$ & $184(2.4)$ & $0.30(0.25-0.35)$ & $<0.001$ \\
\hline Intra-operative complication & $73(1.0)$ & $33(0.4)$ & $0.44(0.29-0.66)$ & $<0.001$ \\
\hline \multicolumn{5}{|l|}{ Postoperative complication } \\
\hline Overall & $823(11.1)$ & 705 (9.3) & $0.82(0.73-0.91)$ & $<0.001$ \\
\hline Cardiac & $96(1.3)$ & $68(0.9)$ & $0.69(0.50-0.94)$ & 0.018 \\
\hline Respiratory & $191(2.6)$ & $105(1.4)$ & $0.53(0.42-0.67)$ & $<0.001$ \\
\hline Vascular & $45(0.6)$ & $30(0.4)$ & $0.65(0.41-1.03)$ & 0.065 \\
\hline Operative wound & $48(0.6)$ & $35(0.5)$ & $0.71(0.46-1.10)$ & 0.121 \\
\hline Genitourinary & $86(1.2)$ & $90(1.2)$ & $1.02(0.76-1.37)$ & 0.907 \\
\hline Miscellaneous medical & $459(6.2)$ & $432(5.7)$ & $0.91(0.79-1.04)$ & 0.173 \\
\hline Miscellaneous surgical & $121(1.6)$ & $122(1.6)$ & $0.98(0.76-1.26)$ & 0.877 \\
\hline Length of stay $>2$ days & $2923(39.6)$ & $1105(14.5)$ & $0.26(0.24-0.28)$ & $<0.001$ \\
\hline In-hospital mortality & $6(0.1)$ & $1(0.01)$ & $0.16(0.02-1.35)$ & 0.092 \\
\hline
\end{tabular}

Abbreviations: $\mathrm{Cl}=$ confidence interval; $\mathrm{OR}=$ odds ratio 
of trifecta (cancer cure, continence, and return of sexual function) at 12 months, demonstrating the feasibility, safety, and efficacy of RARP in low-tointermediate volume centres. In a series from a high-volume centre, trifecta rates at 6 weeks, 3, 6, 12 and 18 months after RARP were 43\%, 65\%, 80\%, 86\% and $91 \%$, respectively. ${ }^{23}$

However, the majority of urologists in Hong Kong are not from high-volume centres, thereby, not being able to achieve these benchmark and commendable results. Thus, it is now debated whether robotic prostatectomy should be limited to high-volume centres of excellence. A randomised trial of open versus robot-assisted RP was commenced in October 2010 in Australia. ${ }^{24}$ Overall, 200 men per treatment arm (400 men in total) are being recruited after diagnosis and before treatment through a major public hospital out-patient clinic and randomised to robotic prostatectomy or open prostatectomy. Clinical outcomes, quality-of-life outcomes, and cost-effectiveness are being critically and prospectively analysed to compare outcomes. ${ }^{24}$ To date, more than 250 patients have been recruited. Results are eagerly awaited. ${ }^{25}$

\section{Robotic partial nephrectomy}

In the recent decade, there has been a stage and size migration of renal tumours. Less than $10 \%$ of new cases present with the classic triad of gross haematuria, loin pain, and mass. The incidence of small renal mass has increased by $3.7 \%$ per year with widely available abdominal imaging such as ultrasonography over the past decade. ${ }^{26}$ Numerous studies have shown that renal insufficiency is associated with increased cardiovascular events, hospitalisation, and mortality, ${ }^{27}$ leading to increasing role of renal-preserving strategies in the treatment of localised renal cell carcinoma. Data from more than 2000 patients who underwent surgery at Memorial Sloan Kettering Cancer Center from 1989 to 2005 showed that radical nephrectomy was an independent factor for new-onset chronic kidney disease. ${ }^{28}$ According to the European Association of Urology guidelines on renal tumour, nephronsparing surgery is the standard procedure for solitary renal tumours measuring up to $7 \mathrm{~cm}$ in diameter. ${ }^{29}$ Benefits of nephron-sparing surgery over radical nephrectomy include equivalent oncological outcome in tumours measuring less than $4 \mathrm{~cm}$, and probably up to $7 \mathrm{~cm}$ in diameter, avoidance of overtreatment of benign lesions which account for up to $20 \%$ of small renal masses, further treatment options available if contralateral kidney recurrence occurs, better quality of life, and decreased overall mortality. ${ }^{30}$ Moreover, both procedures have comparable survival rates. ${ }^{30}$

Open partial nephrectomy (OPN) currently remains the standard procedure for partial nephrectomy. However, OPN is associated with significant morbidity: the muscle-cutting flank incision may involve removal of a lower rib, leading to flank bulge, pain, paraesthesia, and hernia formation. The introduction of laparoscopic partial nephrectomy was aimed at reducing the morbidity associated with OPN.

Laparoscopic partial nephrectomy offers the advantages of shorter length of stay, decreased operative blood loss, and a shorter operating time versus OPN. However, it is associated with longer warm ischaemic time, more postoperative urological complications, and increased number of subsequent procedures. State-of-the-art surgical expertise and technique are prerequisites for laparoscopic partial nephrectomy. ${ }^{31}$ Thus, the procedure is not routinely performed in many centres in view of its prolonged learning curve.

Robot-assisted partial nephrectomy shows promise in bridging the gap between open and laparoscopic approaches, providing similar oncological results to radical nephrectomy and improved morbidity with a shorter learning curve than laparoscopic partial nephrectomy. Robotassisted partial nephrectomy has been shown to be a safe and viable alternative to laparoscopic partial nephrectomy in some published case series, ${ }^{32,33}$ providing equivalent early oncological outcomes to laparoscopic partial nephrectomy, and the additional advantages of decreased hospital stay, less intraoperative blood loss, and shorter warm ischaemic time averaging less than 20 minutes. Moreover, operative parameters for robot-assisted partial nephrectomy are less affected by tumour complexity and surgical expertise of the surgeon as compared with laparoscopic partial nephrectomy. A case series published by our centre ${ }^{34}$ showed that robot-assisted laparoscopic partial nephrectomy was technically feasible, with the advantage of statistically significant decreased warm ischaemic time (31 vs 40 minutes; $\mathrm{P}=0.032$; Table $2^{6}$ ).

\section{Robotic cystectomy}

Radical cystectomy and pelvic lymph node dissection are the standard treatment options for muscle-invasive carcinoma of the bladder. However, this procedure is associated with high morbidity of up to $50 \%$ and mortality of up to $5 \%$, even in centres of excellence. ${ }^{35}$ Data from the Surgical Outcomes Monitoring \& Improvement Program Report of the Hong Kong Hospital Authority showed that radical cystectomy is a surgical procedure associated with the highest morbidity and mortality among all surgical operations in Hong Kong. ${ }^{36}$ From 2009 to 2010 , the 30 -day crude mortality rate was $9.7 \%$, and the 30 -day crude morbidity rate was $65.3 \% .^{36}$

Laparoscopic cystectomy was introduced with the aim of decreasing associated morbidity 
TABLE 2. Comparing outcomes of partial nephrectomy (robotic vs laparoscopic vs open) ${ }^{6}$

\begin{tabular}{lcccc}
\hline Outcome & \multicolumn{3}{c}{ No. (\%) } & P value \\
\cline { 2 - 3 } & RALS (robotic) & LS (laparoscopic) & OS (open) & 0.608 \\
\hline Complications & DS & $11(5.3)$ & $68(3.9)$ & 0.115 \\
\hline Cardiac & DS & $15(7.3)$ & $141(8.0)$ & $<0.001$ \\
\hline Respiratory & 0 & DS & $82(4.6)$ & $<0.001$ \\
\hline Wound & 0 & 0 & $34(2.0)$ & 0.015 \\
\hline Vascular & DS & DS & DS & 0.717 \\
\hline Miscellaneous medical & $28(11.2)$ & $35(16.8)$ & $262(14.8)$ & 0.813 \\
\hline Miscellaneous surgical & $18(7.3)$ & $11(5.1)$ & $89(5.1)$ & Not applicable \\
\hline Death & 0 & 0 & 0 & 0.26 \\
\hline Any complication & $46(18.3)$ & $55(26.7)$ & $512(28.9)$ & 0.922 \\
\hline Blood transfusion & $20(8.1)$ & $13(6.1)$ & $137(7.8)$ & $<0.001$ \\
\hline LOS (days) & $2.8 \pm 2.3$ & $3.6 \pm 3.3$ & $4.5 \pm 6.8$ & 0.006 \\
\hline Routine discharge & $248(97.9)$ & $205(99.2)$ & $1608(90.9)$ & \\
\hline
\end{tabular}

Abbreviations: DS = data suppressed per Nationwide Inpatient Sample for $0<\mathrm{n}<1$ I; LOS = length of stay; LS = laparoscopic surgery; OS = open surgery; RALS = robot-assisted laparoscopic surgery

* Data are shown as mean \pm standard deviation

and length of hospital stay. The first laparoscopic radical cystectomy was performed in $1992 .{ }^{37}$ Case series performed at expert centres showed that when compared with open surgery, laparoscopic cystectomy resulted in a lower morbidity rate with significantly lower intra-operative blood loss and transfusion rates, lower pain scores, and allowing a more rapid resumption of oral intake and a shorter hospital stay. ${ }^{38}$ However, laparoscopic radical cystectomy is technically challenging, with a steep learning curve.

Robot-assisted radical cystectomy (RARC) was introduced as an attempt to offset the high technical skill required for laparoscopic cystectomy, and was the first procedure performed in 2003 by Beecken et al. ${ }^{39}$ A recent retrospective analysis ${ }^{40}$ on consecutive series of patients undergoing radical cystectomy (100 RARCs and 100 open radical cystectomies) with curative intent over a 4-year period suggests that patients undergoing RARC have perioperative oncological outcomes comparable with open radical cystectomies, and lower overall and major complication (Clavien score $\geq 3$ ) rates (35\% vs $57 \%$; $\mathrm{P}=0.001$ and $10 \%$ vs $22 \% ; \mathrm{P}=0.019$, respectively), less blood loss, and shorter hospital stay versus open radical cystectomies. There were no significant differences between the two groups for pathological outcomes, including stage, number of nodes harvested, or positive margin rates. ${ }^{40}$

Although the results for RARC are encouraging, long-term functional and oncological control rates are still unknown. Randomised, multi-institutional comparisons of these techniques will be required before widespread adoption of the procedure.

\section{Other robotic applications in urological surgery}

Reconstructive procedures including pyeloplasty, ureteric reimplantation, appendicovesicostomy, and augmentation enterocystoplasty are increasingly performed with the assistance of the robot. ${ }^{41}$ Data on pyeloplasty showed that the robotic approach is associated with a lower transfusion rate and a shorter length of stay as compared with the open and laparoscopic approaches (Table $3^{6}$ ).

Robot-assisted microsurgery is being utilised to a greater degree in andrology including procedures such as vasectomy reversal, subinguinal varicocelectomy, targeted spermatic cord denervation (for chronic orchialgia), and microsurgical testicular sperm extraction. ${ }^{42}$

\section{Application in gynaecology}

The da Vinci Surgical System was approved for use in gynaecological surgery in the US in 2005. Applications of robotics in gynaecology include hysterectomy, myomectomy, oophorectomy, ovarian cystectomy, resection of endometriosis and lymphadenectomy, with an increasing role of robotic surgery in gynaecological oncology.

Endometrial carcinoma is the most common malignancy of the female reproductive organs and the consensus in the literature is that robotic surgery is preferable to open surgery and is equivalent to laparoscopy in many aspects. ${ }^{43}$ The robotic platform offers distinct advantages in certain populations, such as the morbidly obese, and is becoming a commonly used procedure. ${ }^{43}$ 
TABLE 3. Comparing outcomes of pyeloplasty (robotic vs laparoscopic vs open) ${ }^{6}$

\begin{tabular}{|c|c|c|c|c|}
\hline \multirow[t]{2}{*}{ Outcome } & \multicolumn{3}{|c|}{ No. (\%) } & \multirow[t]{2}{*}{$P$ value } \\
\hline & RALS (robotic) & LS (laparoscopic) & OS (open) & \\
\hline \multicolumn{5}{|l|}{ Complications } \\
\hline Cardiac & DS & 0 & DS & 0.573 \\
\hline Respiratory & DS & 0 & DS & 0.193 \\
\hline Genitourinary & DS & DS & $16(3.7)$ & 0.242 \\
\hline Wound & 0 & 0 & 0 & Not applicable \\
\hline Vascular & 0 & 0 & DS & 0.496 \\
\hline Miscellaneous medical & DS & DS & $16(3.9)$ & 0.913 \\
\hline Miscellaneous surgical & DS & 0 & DS & 0.049 \\
\hline Death & 0 & 0 & 0 & Not applicable \\
\hline Any complication & DS & DS & $38(9.1)$ & 0.505 \\
\hline Blood transfusion & DS & 0 & DS & $<0.001$ \\
\hline LOS (days) ${ }^{*}$ & $2.2 \pm 1.8$ & $2.2 \pm 1.2$ & $3.0 \pm 3.0$ & 0.002 \\
\hline Routine discharge & $166(97.4)$ & $29(100.0)$ & 407 (97.5) & 0.371 \\
\hline
\end{tabular}

Abbreviations: DS = data suppressed per Nationwide Inpatient Sample for $0<\mathrm{n}<1$ I; LOS = length of stay; LS = laparoscopic surgery; OS = open surgery; RALS = robot-assisted laparoscopic surgery

* Data are shown as mean \pm standard deviation

Similarly, in cervical carcinoma, the published data comparing robotic radical hysterectomy to traditional laparoscopy or laparotomy showed that the robotic approach produces more favourable perioperative outcomes, including a lower blood loss, shorter length of stay, and equivalent or lower rates of intra-operative and postoperative complications. ${ }^{44}$ Hysterectomy for benign conditions is one of the most commonly performed procedures in women, with a one in nine chance of a woman undergoing the procedure in her lifetime.$^{45}$ Between 2007 and 2010, the utilisation of robot-assisted hysterectomy for benign gynaecological disorders increased substantially. However, robot-assisted and laparoscopic hysterectomy had similar morbidity profiles, offered little short-term benefit, but resulted in substantially more costs. ${ }^{46} \mathrm{~A} 2012$ Cochrane review of robotic surgery for benign gynaecological diseases showed that robotic surgery was not associated with improved effectiveness or safety, but increased the cost of the procedure substantially. ${ }^{47}$

The existing limited evidence shows that robotic surgery does not benefit women with gynaecological diseases in terms of effectiveness or safety. Further well-designed randomised controlled trials with complete reported data are required to confirm or refute this conclusion.

\section{Application in colorectal surgery}

Laparoscopic colorectal surgery has become the preferred standard of care in colorectal surgery and has been proven to be as safe and effective as open surgery, and associated with a lower blood loss and shorter length of stay. Robotic technology aims to overcome some of the limitations of conventional laparoscopic surgery. However, the role of robotics in colorectal surgery remains controversial. Delaney et $\mathrm{a}^{48}$ compared robotic versus traditional laparoscopic colorectal surgery, and reported that robotic colectomy was a feasible and safe procedure, but involved greater costs and longer operating times.

In a comparative study between robotic versus laparoscopic right hemicolectomy, deSouza et $\mathrm{al}^{49}$ reported that the robotic approach was safe and feasible, but associated with longer operating times and higher costs as compared with pure laparoscopic approach. However, there were similar rates of overall morbidity, lymph node dissection, blood loss, conversion rate, and length of hospital stay in both groups, showing no benefit of robotic approach for right hemicolectomy over laparoscopic surgery.

The emerging role of robotic surgery in colorectal conditions is in rectal pathologies, especially in patients with a narrow pelvis. Total mesorectum excision (TME) has been established as a standard surgical technique in rectal cancer surgery. ${ }^{50}$ Laparoscopic TME in a narrow pelvis and locally advanced disease is a technically demanding procedure, and it is associated with a high conversion rate, high positive surgical margin, and poor continence and erectile function. ${ }^{51,52}$

Robotic nerve-sparing TME was shown in a randomised study to have significantly shorter length of stay (6.9 days vs 8.7 days, $\mathrm{P}<0.001)$ with similar mean operating time, conversion rate, and specimen quality as compared with its counterpart laparoscopic procedure. ${ }^{53}$ In another series by Kim et $\mathrm{al}^{54}$ robotic TME showed a shorter recovery time 
for erectile function as compared with laparoscopic TME (6 vs 12 months). The authors postulated that the precise identification of anatomical planes and smaller neural components was facilitated by magnified view and superior movement of wristed robotic instruments. ${ }^{54}$

Recent studies ${ }^{48-55}$ have confirmed robotic colorectal surgery to be feasible and oncologically safe with potentially significant benefits in rectal surgery. However, we await long-term results concerning oncological outcome.

\section{Application in general surgery}

The application of robotics in general surgery has been evolving, and the number of procedures has been growing over the past decade, especially in bariatric surgery, fundoplication, and hepatobiliary surgery, although robotic approach is not routinely employed for those procedures.

Bariatric procedures can be complex and challenging in view of large patients, large livers, thick abdominal walls and substantial visceral fat, making exposure, dissection and reconstruction difficult. The first robotic bariatric procedure was an adjustable gastric banding procedure performed by Belgian surgeons in September $1998 . .^{56}$ Since then, the robotic approach has become an option to standard laparoscopy. Robotic procedures in bariatric surgery include robotic adjustable gastric banding, robotic sleeve gastrectomy, robotic gastric bypass, and biliopancreatic diversion with duodenal switch.$^{57}$ Robotic bariatric procedures appear to have a decreased rate of gastro-intestinal leaks, lower risk of needing follow-up surgery, and a lower conversion rate to open surgery. ${ }^{58}$

Robotic Heller myotomy for achalasia has been shown to result in fewer oesophageal tears, and improved quality of life after surgery in studies as compared with traditional laparoscopic surgery. ${ }^{59}$

Local data on the feasibility and safety of robotic surgery for hepatocellular carcinoma showed favourable short-term outcomes, including hospital mortality and morbidity rates of $0 \%$ and $7.1 \%$, respectively; the mean hospital stay was 6.2 days. The 2-year overall and disease-free survival rates were $94 \%$ and $74 \%$, respectively. However, the long-term oncological results remain uncertain. ${ }^{60}$

\section{Application in endocrine surgery}

Thyroid surgery is traditionally performed via a collar incision. However, with a large portion of patients being young females, there is a demand for avoiding the transverse cervical incision. This led to the introduction of endoscopic techniques, with the advantages of better cosmetic outcome and reduced paraesthesia of the anterior neck. ${ }^{61}$ However, these endoscopic techniques are technically demanding and time-consuming.

The introduction of the da Vinci Surgical System has further revolutionised the surgical management of thyroid diseases. Robotic surgery overrides the drawbacks of endoscopic surgery, being associated with better visualisation and improved fine manipulation within the deep and narrow cervical space. Better visualisation is achieved through 10 to 12 times of magnification and 3D images, facilitating enhanced precise anatomical dissection. Robotic thyroidectomy is also associated with a shorter learning curve than endoscopic thyroidectomy and causes less musculoskeletal strain to the surgeon. ${ }^{62}$

The use of robots in thyroid surgery is rapidly increasing. Results are promising in case series, with more than 6000 procedures being performed in Korea between 2007 and 2011.63 However, randomised controlled trials comparing robotic with conventional open or endoscopic surgery are needed to assess the long-term oncological outcomes and functional outcomes. ${ }^{63}$

\section{Application in head and neck surgery}

The use of robotics in the field of head and neck surgery was adopted recently, with the first case series published in 2006. ${ }^{64}$ Robotic surgery allows transformation of open surgical management of head and neck cancer to a transoral minimally invasive approach. Robotic approach in head and neck surgery has provided surgeons with the ability to access anatomical locations that were previously managed only via open techniques. This has resulted in decreased overall morbidity and excellent functional results with equivalent oncological outcomes. Transoral robotic surgery provides access to the oropharynx, hypopharynx, larynx, oral cavity, parapharyngeal space, and skull base via the oral aperture. It is useful in resection of the tumour and in free-flap reconstruction.

The advantages of robotic surgery in patients with head and neck cancer are access to anatomical sites not accessible to conventional endoscopy, absence of a neck incision, absence or decreased duration of tracheotomy, absence or decreased duration of nasogastric or gastric feeding tube, and decreased length of hospital stay. ${ }^{65}$

Studies have shown that transoral robotic surgery is a feasible option for surgical management of head and neck tumours, which is associated with reduced morbidity. ${ }^{65,66}$ However, long-term data are required for oncological outcomes.

\section{Application in cardiothoracic surgery}

The first robotic cardiac procedure was performed 
in the US in $1999,{ }^{67}$ and was one of the earliest applications of robotic surgery. Robotic cardiac surgical procedures have been performed to repair and replace the mitral valve, bypass coronary arteries, close atrial septal defects, implant left ventricular pacing leads, and resect intracardiac tumours.

A US study compared robotic sternotomy and thoracotomy approaches to mitral valve surgery outcomes in more than 700 patients with mitral valve disease over a 3-year period. The median cardiopulmonary bypass time was 42 minutes longer for robotic than complete sternotomy, 39 minutes longer than for partial sternotomy, and 11 minutes longer than for right mini-anterolateral thoracotomy $(\mathrm{P}<0.0001)$. Moreover, the robotic procedure was associated with a longer median myocardial ischaemic time compared with conventional procedures $(\mathrm{P}<0.0001)$. The quality of mitral valve repair was similar among matched groups. Neurological, pulmonary, and renal complications were similar among groups. However, the robotic approach was associated with the lowest occurrences of atrial fibrillation and pleural effusion and the shortest hospital stay (median 4.2 days); the hospital stays with robotic surgery were 1.0, 1.6, and 0.9 days shorter than for complete sternotomy, partial sternotomy, and right mini-anterolateral thoracotomy, respectively $(\mathrm{P}<0.001$ for all comparisons). This series showed that robotic repair of posterior mitral valve leaflet prolapse is as safe and effective as conventional approaches. Technical complexity and longer operating times for robotic repair are compensated for by lesser invasiveness and shorter hospital stay ${ }^{68}$

Robotic thoracic procedures include resection of primary lung cancer, oesophageal tumours, thymic diseases, and mediastinal tumours. ${ }^{69}$ Another US series with 168 patients which compared patients who underwent robotic pulmonary resection with propensity-matched controls undergoing lobectomy by rib- and nerve-sparing thoracotomy showed that the robotic group had reduced morbidity ( $27 \%$ vs $38 \%$; $\mathrm{P}=0.05$ ), lower mortality ( $0 \%$ vs $3.1 \%$; $\mathrm{P}=0.11$ ), improved mental quality of life (53 vs 40 ; $\mathrm{P}<0.001$ ), and shorter hospital stay (2.0 vs 4.0 days; $\mathrm{P}=0.02$ ). Moreover, with the additional technical modification of completely portal robotic lobectomy with four arms, both the median operating time (3.7 vs 1.9 hours; $\mathrm{P}<0.001$ ) and conversion rates to traditional thoracotomy $(12 / 62$ vs $1 / 106 ; \mathrm{P}<0.001)$ were lowered. ${ }^{69}$

Despite being one of the first specialties to utilise the robotic technology, it is still unclear whether the technical advantages bring about direct merits for patients. Results have been mixed, with no unequivocal evidence on benefits of the robotic approach. Further evidence is awaited on the use of robotics in the cardiothoracic field.

\section{Future applications for robotics}

Laparoendoscopic single-site surgery (LESS) and natural orifice transluminal endoscopic surgery are novel techniques that have the potential to further minimise the invasiveness and morbidity of surgery. However, the technical difficulty of the procedure is increased with the need for specialised instruments. Robotic technology is rapidly evolving, and with the development of new robotic prototypes for single-port surgery, it is expected that roboticLESS will move forward with the goal of minimising complications and improving outcomes. ${ }^{70}$

\section{Conclusion}

Robotic surgery with the da Vinci Surgical System is increasingly being applied in a wide range of surgical specialties, especially in urology. It aims to improve outcomes as compared with open surgery, and to overcome the limitations of laparoscopic/ thoracoscopic techniques. Despite the increasing popularity of robotic surgery, except in RARP, there is no unequivocal evidence to show the superiority of robotic surgery over traditional laparoscopic surgery in other surgical procedures. Cost-effectiveness is also an issue due to the high installation and maintenance costs. We eagerly await the introduction of different robotic systems by competitors. Further randomised studies are required to ascertain the long-term results and potential benefits of robotic surgery. We eagerly await the results of the ongoing randomised trial of open versus robotic RP from Australia.

\section{Declaration}

No conflicts of interest were declared by authors.

\section{References}

1. Menon M, Tewari A, Baize B, Guillonneau B, Vallancien G. Prospective comparison of radical retropubic prostatectomy and robot-assisted anatomic prostatectomy: the Vattikuti Urology Institute experience. Urology 2002;60:864-8.

2. Intuitive Surgical company website. Available from: http:// www.intuitivesurgical.com/company/media/publications/ da-vinci-surgery-high-LOE-publications-en-031114.pdf. Accessed Apr 2014.

3. Pugin F, Bucher P, Morel P. History of robotic surgery: from AESOP $^{\circledR}$ and ZEUS $^{\circledR}$ to da Vinci ${ }^{\circledR}$. J Visc Surg 2011;148(5 Suppl):e3-8.

4. Abbou CC, Hoznek A, Salomon L, et al. Remote laparoscopic radical prostatectomy carried out with a robot. Report of a case [in French]. Prog Urol 2000;10:5203.

5. Smith JA Jr, Herrell SD. Robotic-assisted laparoscopic prostatectomy: do minimally invasive approaches offer significant advantages? J Clin Oncol 2005;23:8170-5.

6. Yu HY, Hevelone ND, Lipsitz SR, Kowalczyk KJ, Hu 
JC. Use, costs and comparative effectiveness of robotic assisted, laparoscopic and open urological surgery. J Urol 2012;187:1392-8.

7. Barbash GI, Glied SA. New technology and health care costs - the case of robot-assisted surgery. N Engl J Med 2010;363:701-4.

8. Ahmed K, Ibrahim A, Wang TT, et al. Assessing the cost effectiveness of robotics in urological surgery-a systematic review. BJU Int 2012;110:1544-56.

9. Menon M, Shrivastava A, Tewari A, et al. Laparoscopic and robot assisted radical prostatectomy: establishment of a structured program and preliminary analysis of outcomes. J Urol 2002;168:945-9.

10. Benway BM, Bhayani SB, Rogers CG, et al. Robot assisted partial nephrectomy versus laparoscopic partial nephrectomy for renal tumors: a multi-institutional analysis of perioperative outcomes. J Urol 2009;182:86672 .

11. Dasgupta P, Rimington P, Murphy D, Elhage O, Challacombe B, Khan MS. Robotically assisted radical cystectomy. BJU Int 2008;101:1489-90.

12. Ferlay J, Shin HR, Bray F, Forman D, Mathers C, Parkin DM. GLOBOCAN 2008 v1.2: cancer incidence and mortality worldwide. IARC CancerBase No. 10. Lyon, France: IARC Press; 2010.

13. Yip SK, Sim HG. Robotic radical prostatectomy in east Asia: development, surgical results and challenges. Curr Opin Urol 2010;20:80-5.

14. Hospital Authority, Hong Kong. Hong Kong Cancer Registry. 2010. Available from: http://www3.ha.org. hk/cancereg/Summary\%20of\%20CanStat\%202010.pdf. Accessed Apr 2014.

15. Bill-Axelson A, Holmberg L, Ruutu M, et al. Radical prostatectomy versus watchful waiting in early prostate cancer. N Engl J Med 2005;352:1977-84.

16. Bill-Axelson A, Holmberg L, Ruutu M, et al. Radical prostatectomy versus watchful waiting in early prostate cancer. N Engl J Med 2011;364:1708-17.

17. Schuessler WW, Schulam PG, Clayman RV, Kavoussi LR. Laparoscopic radical prostatectomy: initial short-term experience. Urology 1997;50:854-7.

18. Guillonneau B, Vallancien G. Laparoscopic radical prostatectomy: initial experience and preliminary assessment after 65 operations. Prostate 1999;39:71-5.

19. Ahlering TE, Skarecky D, Lee D, Clayman RV. Successful transfer of open surgical skills to a laparoscopic environment using a robotic interface: initial experience with laparoscopic radical prostatectomy. J Urol 2003;170:1738-41.

20. Skarecky DW. Robotic-assisted radical prostatectomy after the first decade: surgical evolution or new paradigm. ISRN Urol 2013;2013:157379.

21. Trinh QD, Sammon J, Sun M, et al. Perioperative outcomes of robot-assisted radical prostatectomy compared with open radical prostatectomy: results from the nationwide inpatient sample. Eur Urol 2012;61:679-85.

22. Yip $\mathrm{KH}$, Yee $\mathrm{CH}, \mathrm{Ng} \mathrm{CF}$, et al. Robot-assisted radical prostatectomy in Hong Kong: a review of 235 cases. J Endourol 2012;26:258-63.

23. Patel VR, Coelho RF, Chauhan S, et al. Continence, potency and oncological outcomes after robotic-assisted radical prostatectomy: early trifecta results of a high-volume surgeon. BJU Int 2010;106:696-702.
24. Gardiner RA, Coughlin GD, Yaxley JW, et al. A progress report on a prospective randomised trial of open and robotic prostatectomy. Eur Urol 2014;65:512-5.

25. Gardiner RA, Yaxley J, Coughlin G, et al. A randomised trial of robotic and open prostatectomy in men with localised prostate cancer. BMC Cancer 2012;12:189.

26. Hock LM, Lynch J, Balaji KC. Increasing incidence of all stages of kidney cancer in the last 2 decades in the United States: an analysis of surveillance, epidemiology and end results program data. J Urol 2002;167:57-60.

27. Go AS, Chertow GM, Fan D, McCulloch CE, Hsu $\mathrm{CY}$. Chronic kidney disease and the risks of death, cardiovascular events, and hospitalization. N Engl J Med 2004;351:1296-305.

28. Huang WC, Levey AS, Serio AM, et al. Chronic kidney disease after nephrectomy in patients with renal cortical tumours: a retrospective cohort study. Lancet Oncol 2006;7:735-40.

29. European Association of Urology. Renal Cell Cancer Guidelines, 2013 update. Available from: http://www. uroweb.org/gls/pdf/10_Renal_Cell_Carcinoma_LR.pdf. Accessed Apr 2014.

30. Weight CJ, Larson BT, Fegany AF, et al. Nephrectomy induced chronic renal insufficiency is associated with increased risk of cardiovascular death and death from any cause in patients with localized cT1b renal masses. J Urol 2010;183:1317-23.

31. Gill IS, Kavoussi LR, Lane BR, et al. Comparison of 1,800 laparoscopic and open partial nephrectomies for single renal tumors. J Urol 2007;178:41-6.

32. Benway BM, Bhayani SB, Rogers CG, et al. Robotassisted partial nephrectomy versus laparoscopic partial nephrectomy for renal tumors: a multi-institutional analysis of perioperative outcomes. J Urol 2009;182:866-72.

33. Khalifeh A, Autorino R, Hillyer SP, et al. Comparative outcomes and assessment of trifecta in 500 robotic and laparoscopic partial nephrectomies: a single surgeon experience. J Urol 2013;189:1236-42.

34. Cho CL, Ho KL, Chu SS, Tam PC. Robot-assisted versus standard laparoscopic partial nephrectomy: comparison of perioperative outcomes from a single institution. Hong Kong Med J 2011;17:33-8.

35. Stein JP, Lieskovsky G, Cote R, et al. Radical cystectomy in the treatment of invasive bladder cancer: long-term results in 1,054 patients. J Clin Oncol 2001;19:666-75.

36. Hospital Authority, Hong Kong. Surgical Outcomes Monitoring \& Improvement Program (SOMIP) Report Volume 4;2012.

37. Parra RO, Andrus CH, Jones JP, Boullier JA. Laparoscopic cystectomy: initial report on a new treatment for the retained bladder. J Urol 1992;148:1140-4.

38. Guillotreau J, Gamé X, Mouzin M, et al. Radical cystectomy for bladder cancer: morbidity of laparoscopic versus open surgery. J Urol 2009;181:554-9.

39. Beecken WD, Wolfram M, Engl T, et al. Robotic-assisted laparoscopic radical cystectomy and intra-abdominal formation of an orthotopic ileal neobladder. Eur Urol 2003;44:337-9.

40. Kader AK, Richards KA, Krane LS, Pettus JA, Smith JJ, Hemal AK. Robot-assisted laparoscopic vs open radical cystectomy: comparison of complications and perioperative oncological outcomes in 200 patients. BJU Int 2013;112:E290-4 
41. Gundeti MS, Kojima Y, Haga N, Kiriluk K. Robotic-assisted laparoscopic reconstructive surgery in the lower urinary tract. Curr Urol Rep 2013;14:333-41.

42. Parekattil SJ, Gudeloglu A. Robotic assisted andrological surgery. Asian J Androl 2013;15:67-74.

43. Gaia G, Holloway RW, Santoro L, Ahmad S, Di Silverio E, Spinillo A. Robotic-assisted hysterectomy for endometrial cancer compared with traditional laparoscopic and laparotomy approaches: a systematic review. Obstet Gynecol 2010;116:1422-31.

44. Weinberg L, Rao S, Escobar PF. Robotic surgery in gynecology: an updated systematic review. Obstet Gynecol Int 2011;2011:852061.

45. ACOG Committee Opinion No. 444: choosing the route of hysterectomy for benign disease. Obstet Gynecol 2009;114:1156-8.

46. Wright JD, Ananth CV, Lewin SN, et al. Robotically assisted vs laparoscopic hysterectomy among women with benign gynecologic disease. JAMA 2013;309:689-98.

47. Liu H, Lu D, Wang L, Shi G, Song H, Clarke J. Robotic surgery for benign gynaecological disease. Cochrane Database Syst Rev 2012;(2):CD008978.

48. Delaney CP, Lynch AC, Senagore AJ, Fazio VW. Comparison of robotically performed and traditional laparoscopic colorectal surgery. Dis Colon Rectum 2003;46:1633-9.

49. deSouza AL, Prasad LM, Park JJ, Marecik SJ, Blumetti J, Abcarian H. Robotic assistance in right hemicolectomy: is there a role? Dis Colon Rectum 2010;53:1000-6.

50. Heald RJ, Moran BJ, Ryall RD, Sexton R, MacFarlane JK. Rectal cancer: the Basingstoke experience of total mesorectal excision, 1978-1997. Arch Surg 1988;133:8949.

51. Guillou PJ, Quirke P, Thorpe H, et al. Short-term endpoints of conventional versus laparoscopic-assisted surgery in patients with colorectal cancer (MRC CLASICC trial): multicentre, randomised controlled trial. Lancet 2005;365:1718-26.

52. Kennedy GD, Heise C, Rajamanickam V, Harms B, Foley EF. Laparoscopy decreases postoperative complication rates after abdominal colectomy: results from the national surgical quality improvement program. Ann Surg 2009;249:596-601.

53. Baik SH, Ko YT, Kang CM, et al. Robotic tumor-specific mesorectal excision of rectal cancer: short-term outcome of a pilot randomized trial. Surg Endosc 2008;22:1601-8.

54. Kim JY, Kim NK, Lee KY, Hur H, Min BS, Kim JH. A comparative study of voiding and sexual function after total mesorectal excision with autonomic nerve preservation for rectal cancer: laparoscopic versus robotic surgery. Ann Surg Oncol 2012;19:2485-93.

55. Liao G, Zhao Z, Lin S, et al. Robotic-assisted versus laparoscopic colorectal surgery: a meta-analysis of four randomized controlled trials. World J Surg Oncol 2014;12:122.

56. Cadiere GB, Himpens J, Vertruyen M, Favretti F. The world's first obesity surgery performed by a surgeon at a distance. Obes Surg 1999;9:206-9.

57. Wilson EB, Sudan R. The evolution of robotic bariatric surgery. World J Surg 2013;37:2756-60.

58. Hagen ME, Pugin F, Chassot G, et al. Reducing cost of surgery by avoiding complications: the model of robotic Roux-en-Y gastric bypass. Obes Surg 2012;22:52-61.

59. Horgan S, Galvani C, Gorodner MV, et al. Robotic-assisted Heller myotomy versus laparoscopic Heller myotomy for the treatment of esophageal achalasia: multicenter study. J Gastrointest Surg 2005;9:1020-30.

60. Lai EC, Yang GP, Tang CN. Robot-assisted laparoscopic liver resection for hepatocellular carcinoma: short-term outcome. Am J Surg 2013;205:697-702.

61. Kang SW, Jeong JJ, Yun JS, et al. Gasless endoscopic thyroidectomy using trans-axillary approach; surgical outcome of 581 patients. Endocr J 2009;56:361-9.

62. Lee J, Yun JH, Choi UJ, Kang SW, Jeong JJ, Chung WY. Robotic versus endoscopic thyroidectomy for thyroid cancers: a multi-institutional analysis of early postoperative outcomes and surgical learning curves. J Oncol 2012;2012:734541.

63. Lee J, Chung WY. Robotic thyroidectomy and neck dissection: past, present, and future. Cancer J 2013;19:15161.

64. O'Malley BW Jr, Weinstein GS, Snyder W, Hockstein NG. Transoral robotic surgery (TORS) for base of tongue neoplasms. Laryngoscope 2006;116:1465-72.

65. Hans S, Delas B, Gorphe P, Ménard M, Brasnu D. Transoral robotic surgery in head and neck cancer. Eur Ann Otorhinolaryngol Head Neck Dis 2012;129:32-7.

66. Van Abel KM, Moore EJ. The rise of transoral robotic surgery in the head and neck: emerging applications. Expert Rev Anticancer Ther 2012;12:373-80.

67. Loulmet D, Carpentier A, d'Attellis N, et al. Endoscopic coronary artery bypass grafting with the aid of robotic assisted instruments. J Thorac Cardiovasc Surg 1999;118:410.

68. Mihaljevic T, Jarrett CM, Gillinov AM, et al. Robotic repair of posterior mitral valve prolapse versus conventional approaches: potential realized. J Thorac Cardiovasc Surg 2011;141:72-80.e1-4.

69. Cerfolio RJ, Bryant AS, Skylizard L, Minnich DJ. Initial consecutive experience of completely portal robotic pulmonary resection with 4 arms. J Thorac Cardiovasc Surg 2011;142:740-6.

70. Autorino R, Kaouk JH, Stolzenburg JU, et al. Current status and future directions of robotic single-site surgery: a systematic review. Eur Urol 2013;63:266-80. 